\title{
Utilização de Artefatos de Contabilidade Gerencial nas Sociedades Cooperativas Agropecuárias de Minas Gerais e sua Relação com Porte e Desempenho Financeiro
}

\begin{abstract}
Resumo
O objetivo deste estudo foi verificar a utilização dos artefatos tradicionais e modernos de contabilidade gerencial em cooperativas agropecuárias e analisar a relação com seu porte e desempenho financeiro. A pesquisa contribuiu para a literatura, evidenciando que, apesar de analisar um ramo específico, os resultados se mostraram similares aos estudos anteriores realizados no Brasil e no exterior. O estudo é quantitativo, empírico-analítico e survey. Os dados foram coletados por meio de questionário semiestruturado, utilizado em pesquisas anteriores, com adaptações para este estudo. O questionário foi enviado por e-mail em abril de 2011 para 92 cooperativas que, depois de contatadas, se dispuseram a participar da pesquisa, obtendo-se, ao final, 69 respostas. A população total é composta por 203 cooperativas. Os dados foram submetidos ao teste estatístico não paramétrico de significância de médias de duas amostras independentes. As evidências empíricas indicam a utilização dos artefatos pelas cooperativas e que, em relação ao desempenho e ao porte, não houve diferença estatisticamente significativa entre as cooperativas que utilizam artefatos modernos e/ou tradicionais de contabilidade gerencial.
\end{abstract}

Palavras-chave: Contabilidade Gerencial; Artefatos Modernos e Tradicionais; Cooperativas Agropecuárias.
Antonio Marcos dos Reis

Mestre em Ciências Contábeis (Fucape e Diretor Administrativo Financeiro da Cooperativa Central Mineira de Laticínios Ltda.-CEMIL. Contato: Av. das Indústrias, 1090, Distrito Industrial II, Patos de Minas, MG, CEP: 38706-730.

E-mail: antonio.marcos@cemil.com.br

Aridelmo José Campanharo Teixeira ${ }^{1}$ Doutor em Controladoria e Contabilidade (USP) e Professor da Fucape Business School. Contato: Av. Fernando Ferrari, 1358, Boa Vista, Vitória, ES, CEP 29075-505.

E-mail: aridelmo@fucape.br

10 segundo autor agradece à FAPES - Fundação de Amparo a Pesquisa no Espírito Santo pelo apoio proporcionado ao projeto de pesquisa que originou o trabalho. 


\section{Introdução}

Para apoio ao gestor no desempenho de suas atividades, a contabilidade gerencial, entendida como "o produto do processo de produzir informação operacional e financeira para gestores dentro de uma organização" (Soutes, 2006, p. 9), conta com métodos, filosofias e modelos de gestão, ferramentas, sistemas e instrumentos denominados artefatos (Borinelli, 2006; Soutes, 2006).

Estudos no exterior, como Sulaiman, Ahmad e Alwi (2004), Chenhall e Langfield-Smith (1998), e no Brasil, como Soutes (2006), Soutes e Guerreiro (2007), Espejo (2008), Teixeira, Gonzaga, Santos e Nossa (2011), Guerreiro, Cornachione e Soutes (2010), Reginato (2010), Matos (2010) e Gonzaga, Da Luz, Guimarães e Valerio (2010), foram feitos averiguando a utilização dos artefatos (ou ferramentas) de contabilidade gerencial.

Os artefatos têm sido divididos em tradicionais e modernos, observando-se ainda a classificação de estágios feita pelo International Management Accounting Practice - IMAP 1 (Sulaiman et al., 2004; Soutes \& De Zen, 2005). São considerados artefatos tradicionais: custeio variável, custeio-padrão, custeio por absorção, orçamento, descentralização, valor presente, moeda constante e preço de transferência. São considerados artefatos modernos: teoria das restrições, custeio baseado em atividades (ABC), benchmarking, just-in-time, kaizen, custeio-meta, simulação, balanced scorecard, Valor Econômico Adicionado (EVA) e Gecon.

Os estudos que abordam os artefatos, de forma isolada e/ou conjunta, procuram ainda evidências da relação entre a sua utilização com o porte e o desempenho financeiro das entidades (Soutes, 2006; Espejo, 2008; Teixeira et al., 2009; Reginato, 2010; Matos, 2010; Gonzaga et al., 2010). Soutes (2006) e Teixeira et al., (2009) evidenciaram resultados divergentes quanto ao desempenho financeiro. Divergência também foi encontrada em estudos que identificaram a prevalência da utilização dos artefatos tradicionais (Chenhall \& Langfield-Smith, 1998; Sulaiman et al., 2004), afirmando, pois, um gap entre teoria e utilização dos artefatos, comparados a estudos que identificaram a prevalência da utilização dos artefatos modernos (Soutes \& Guerreiro, 2007), indicando uma defasagem sobre a existência desse gap.

O presente estudo justifica-se como forma de contribuição às pesquisas já feitas, às quais se acrescentarão os testes em cooperativas agropecuárias de um estado da Federação. Utilizando-se de cooperativas de apenas um segmento, podem-se avaliar as diferenças de porte, rentabilidade e estratégias de um setor específico, diferentemente dos estudos anteriores, cujas amostras continham empresas de segmentos diversos.

O objetivo foi verificar a utilização dos artefatos de contabilidade gerencial, tradicionais e modernos, nas cooperativas e analisar se há relação com o seu porte e desempenho financeiro. A questão de pesquisa é: Qual a relação entre a escolha de determinados artefatos de contabilidade gerencial com o porte e o desempenho econômico-financeiro das cooperativas?

Além deste introdutório, o trabalho está dividido em mais cinco capítulos. O capítulo 2 apresenta o referencial teórico, com os conceitos de cooperativas, cooperativas agropecuárias, contabilidade gerencial e artefatos; o capítulo 3, estudos anteriores e as hipóteses; o capítulo 4, a metodologia com o tipo de pesquisa, coleta de dados, amostra e método de análise; o capítulo 5 apresenta a análise dos dados e a comparação com estudos anteriores; e o capítulo 6, as conclusões extraídas da análise estatística.

\section{Referencial Teórico}

\subsection{Sociedades Cooperativas}

A Lei n. ${ }^{\circ}$ 5.764/71, no seu Art. $4^{\circ}$, define as sociedades cooperativas como "[...] sociedades de pessoas, com forma e natureza jurídica próprias, de natureza civil, não sujeitas à falência, constituídas para prestar serviços aos associados, distinguindo-se das demais sociedades" por uma série de características, dentre elas a adesão voluntária e livre, a incessibilidade de quotas a terceiros estranhos à sociedade e à singularidade de voto, exceto para centrais, federações e confederações (Lei n. ${ }^{\circ} 5.764,1971$ ). 
Para Carvalho e Bialoskorski Neto (2007, p. 1):

As cooperativas agropecuárias são organizações formadas por produtores rurais, e importantes na agricultura, pois possibilitam para o produtor a armazenagem e comercialização da produção, os ganhos de escala, o poder de barganha, a industrialização da matéria-prima permitindo a agregação de valor, bem como possibilitam também a difusão e a democratização do acesso à tecnologia e à assistência técnica.

Os dados do Anuário do Cooperativismo Mineiro de 2010, editado pela Organização das Cooperativas do Estado de Minas Gerais [OCEMG] (2010, p. 16), informam que 8,7 de cada 100 pessoas economicamente ativas vinculam-se a alguma cooperativa no estado. Informam também que $6,4 \%$ do PIB mineiro, equivalente a 18,5 bilhões de reais, provêm do cooperativismo, sendo $48,31 \%$ desse valor proveniente do cooperativismo agropecuário. Consta ainda no Anuário que o cooperativismo agropecuário, com movimentação de 8,9 bilhões de reais anuais, representa 10,7\% do PIB agropecuário do estado, sendo o setor responsável pela produção de $44,7 \%$ do leite, $43,7 \%$ do café e, aproximadamente, $22 \%$ da produção de aves, abacate, trigo e alho.

As cooperativas agropecuárias, em seus respectivos segmentos, concorrem com empresas multinacionais e grandes empresas nacionais e, nesse contexto, devem ser gerenciadas de forma profissional para sua sobrevivência.

\subsection{Sistemas de Controle Gerencial}

De acordo com Davila e Foster (2007, p. 908), “em estágios iniciais as empresas são uma lousa aberta em relação aos Sistemas de Controle Gerencial" e precisam definir quais serão implementados. Dizem ainda (Davila \& Foster, 2007, p. 909) que o "crescimento da empresa torna o esforço de observação direta caro demais, motivando o monitoramento através de um adequado Sistema de Controle Gerencial (SCG)".

Para Otley (1980, p. 413), "a abordagem da contingência para a contabilidade gerencial é baseada na premissa de que não há sistema de contabilidade universalmente apropriado, o qual se aplica igualmente para todas as organizações em todas as circunstâncias." Também para Gonzaga et al., (2010, p. 2), quanto às ferramentas do Sistema de Controle Gerencial, "não existe um padrão sobre quais devem ser utilizadas pela organização. Ademais, a estrutura do SCG pode variar em função das estratégias adotadas, necessidades organizacionais, bem como dos fatores que podem influenciá-lo."

A contabilidade gerencial, como parte integrante dos Sistemas de Controle Gerencial, tem o papel de gerar as informações financeiras e não financeiras para os gestores tomarem decisões e para assegurar a utilização dos recursos de acordo com sua finalidade (Horngren, Foster \& Datar, 2000; Atkinson, Banker \& Kaplan, 2000; Soutes, 2006).

\subsection{Contabilidade Gerencial}

De acordo com Soutes (2006, p. 9), "Por 'contabilidade gerencial' entende-se o produto do processo de produzir informação operacional e financeira para gestores dentro de uma organização." Conforme Atkinson et al. (2000, p. 36), "é o processo de identificar, mensurar, reportar e analisar informações sobre os eventos econômicos das empresas."

O Institute of Management Accountants (IMA) emitiu, em 1998, um relatório denominado "International Accounting Management Practice 1" (IMAP 1) (Internacional Federation of Accountants, 1998). Nesse relatório, a contabilidade gerencial foi caracterizada em quatro estágios evolutivos e, à medida que evoluiu, evidenciou-se a alteração de seu posicionamento na estrutura das organizações, deixando de ser uma atividade meramente técnica para tornar-se atividade criadora de valor, parte integrante da gestão, conforme demonstrado na Figura 1. 


\section{Estágios evolutivos}

Na fase 1, antes de 1950, o foco foi a determinação de custos e o controle financeiro, por meio da utilização da tecnologia de orçamentação e contabilização de custos.

Na fase 2, iniciada em 1965, o foco mudou para o fornecimento de informações para o planejamento gerencial e controle, por meio da utilização de tecnologias, como análise de decisão e contabilidade por responsabilidade.

$\mathrm{Na}$ fase 3, iniciada em 1985, a atenção estava voltada para a redução dos desperdícios de recursos usados nos processos de negócio, por meio da utilização de análise de processos e tecnologias de gestão de custos.

Na fase 4, iniciada em 1995, a atenção se deslocava para a geração ou criação de valor por meio da utilização eficaz de recursos e do uso de tecnologias, as quais avaliam os direcionadores de valor para o cliente, valor para o acionista e inovação organizacional.

\section{Posição na estrutura organizacional}

No estágio 1, era vista como uma atividade técnica necessária para perseguir os objetivos organizacionais.

No estágio 2, passa a ser vista como uma atividade gerencial, mas em um papel de assessoria, fornecendo informação para planejamento e controle.

Nos estágios 3 e 4, tem sido vista como parte integrante do processo de gestão, com informações em tempo real tornadas disponíveis diretamente para gerenciamento e com a diferença entre equipe e gerência de linha, tornando-se progressivamente desfocada. O foco na utilização de recursos (inclusive informação) para criar valor é parte integrante do processo de gerenciamento nas organizações.

Figura 1. Estágios Evolutivos e Posição da Contabilidade Gerencial na Estrutura da Organização de Acordo com o Imap 1

Fonte: Adaptado de IMAP 1 (1998)

\subsection{Artefatos}

Para Borinelli (2006, p.184):

[...] a Controladoria e a Contabilidade Gerencial, para desempenharem suas atividades e funções, especialmente no que se refere a mensurar e a reportar os eventos econômicos, precisam empregar métodos (de mensuração, etc.) e utilizar instrumentos (de avaliação de desempenhos, por exemplo). Estes métodos, "filosofias" de gestão e instrumentos vêm sendo denominados por vários autores, de artefatos.

Soutes (2006, p. 9) afirma que:

"Por artefatos entende-se (...) atividades, ferramentas, instrumentos, filosofias de gestão, filosofias de produção, modelos de gestão e sistemas que possam ser utilizados pelos profissionais da Contabilidade gerencial no exercício de suas funções".

Ainda para Soutes (2007), vários artefatos modernos foram desenvolvidos pelos pesquisadores com o objetivo de dar, na ótica de Shank e Govindarajan (1997, p. 29), uma "perspectiva mais abrangente que a contabilidade gerencial tradicional".

Para Chenhall e Langfield-Smith (1998), "a intensificação dos desafios em função do aumento da competição global" fez com que a contabilidade gerencial, como resposta às mudanças e para manter sua relevância, criasse uma gama de novas técnicas gerenciais. Ainda para Chenhall e Langfield-Smith (1998), "as práticas tradicionais são focadas em questões internas e financeiramente orientadas. As práticas modernas combinam informação financeira e não financeira, com foco explícito na estratégia." 


\begin{tabular}{cl}
\hline Estágios & \multicolumn{1}{c}{ Artefatos } \\
\hline $1^{\circ}$ Estágio & Custeio por absorção, custeio variável, custeio padrão e retorno sobre investimento. \\
\hline $2^{\circ}$ Estágio & Preço de transferência, moeda constante, valor presente, orçamento e descentralização. \\
\hline $3^{\circ}$ Estágio & $\begin{array}{l}\text { Custeio Baseado em Atividades (ABC), custeio meta (target costing), benchmarking, Kaizen, just-in-time (IIT), } \\
\text { teoria das restrições, planejamento estratégico e gestão baseada em atividades (ABM). }\end{array}$ \\
\hline $4^{\circ}$ Estágio & EVA (Economic Vallue Added), simulação, Gecon e balanced scorecard. \\
\hline
\end{tabular}

Figura 2. Artefatos de Contabilidade Gerencial por Estágios

Fonte: Adaptado de Soutes (2006)

Soutes (2006) divide as categorias em tradicionais e modernas, seguindo a metodologia sugerida por Soutes e De Zen (2005) e a distribuição de categorias entre tradicionais e modernas sugerida por Sulaiman et al. (2004), observando ainda a classificação de estágios feita pelo International Management Accounting Practice (IMAP 1).

Soutes (2006, p. 9) considera como "artefatos tradicionais de contabilidade gerencial aqueles que satisfaçam aos objetivos dos $1^{\circ}$ e $2^{\circ}$ estágios da contabilidade gerencial propostos pelo Institute of Management Accountants (IMA) [...]" e modernos, aqueles que satisfaçam aos do $3^{\circ}$ e $4^{\circ}$ estágios. Os artefatos são segregados, de acordo com Soutes (2006, p. 24), conforme consta da Figura 2.

\section{Hipóteses}

Chenhall e Langfield-Smith (1998) apresentaram estudo sobre a adoção e benefícios das práticas contábeis gerenciais nas 78 das maiores indústrias australianas divulgadas pela Business Review Weekly. Os autores encontraram evidências de maior adoção dos artefatos tradicionais em relação aos modernos e de maiores benefícios na utilização dos artefatos tradicionais.

Sulaiman et al. (2004), por meio da revisão da literatura sobre a utilização dos artefatos de contabilidade gerencial em empresas de quatro países asiáticos (Singapura, Malásia, China e Índia), identificaram a falta de utilização dos artefatos modernos de contabilidade gerencial, com forte permanência da utilização dos artefatos tradicionais.

Soutes e Guerreiro (2007), em pesquisa com as 500 empresas brasileiras recordistas em vendas no ano de 2004, de acordo com o caderno Melhores e Maiores da revista Exame, de julho de 2005, ano-base 2004, e 44 empresas indicadas ao prêmio ANEFAC-FIPECAFI-SERASA, Troféu Transparência, entre os anos-base de 1996 e 2004, identificaram que 52\% utilizavam os artefatos de contabilidade gerencial modernos e apresentavam desempenho diferenciado daquelas que utilizavam os artefatos de contabilidade gerencial tradicionais.

Entretanto, Teixeira et al. (2009) analisaram a utilização dos artefatos de contabilidade tradicionais e modernos nas 200 maiores empresas do Estado do Espírito Santo, segundo ranking da revista Findes, e não encontraram evidências de relação entre o uso de um ou outro artefato e o desempenho financeiro das empresas. De acordo com os autores, o resultado difere do trabalho anterior realizado por Soutes e Guerreiro (2007).

Por sua vez, Gonzaga et al., (2010), também utilizando como referência as 200 maiores empresas do Estado do Espírito Santo, segundo ranking da revista Findes, encontraram relação entre o tamanho (representado pelo ativo total) e a maior quantidade e intensidade de utilização de alguns artefatos de contabilidade gerencial.

Em conformidade com os resultados dos estudos já elaborados por Sulaiman et al. (2004), Soutes (2006), Soutes e Guerreiro (2007), Teixeira et al. (2009) e Guerreiro et al. (2010), são três hipóteses a serem testadas. 
- H1: As cooperativas agropecuárias do estado de Minas Gerais não utilizam artefatos modernos de contabilidade gerencial.

- H2: A utilização dos artefatos modernos de contabilidade gerencial implica em porte diferenciado.

- H3: A utilização dos artefatos modernos de contabilidade gerencial implica em desempenho financeiro diferenciado.

\section{Aspectos Metodológicos}

Trata-se, quanto aos métodos, de pesquisa empírico-analítica (Martins, 2000, p. 26) e survey (Creswell, 2007; Martins, 2000).

A amostra é considerada não probabilística intencional ou por conveniência (Martins, 2000; Oliveira et al., 2003).

De acordo com o Anuário do Cooperativismo Mineiro, editado pela Organização das Cooperativas do Estado de Minas Gerais (OCEMG) (2010, p. 14), em agosto de 2010, a população era de 203 cooperativas agropecuárias no Estado de Minas Gerais.

O rol com nome, endereço, telefone e e-mail das cooperativas agropecuárias constou do Anuário do Cooperativismo Mineiro, editado pela Organização das Cooperativas do Estado de Minas Gerais (OCEMG) (2010, p. 116). Buscou-se, por telefone, contato com todas. O contador foi inicialmente procurado e informado da pesquisa, solicitando-lhe, posteriormente, autorização para o envio de e-mail com o questionário. Além do contador, sempre que possível ou solicitado, o e-mail foi enviado para gerentes, diretores ou presidentes das cooperativas.

Do total que foi possível contatar, pois, por vezes, o telefone informado não foi atendido, 92 cooperativas autorizaram o envio do questionário e se dispuseram a participar, com algumas ressalvando que só responderiam se houvesse autorização da diretoria. O questionário foi enviado por e-mail em 7 de abril de 2011 para essas 92 cooperativas. Para facilitar o preenchimento dos dados para o respondente, o mesmo questionário foi disponibilizado pelo link do programa "Google Docs". Até o dia 19 de outubro de 2011, 69 questionários foram recebidos.

O questionário foi estruturado em 13 blocos. Os seis primeiros blocos foram compostos das questões desenvolvidas por Soutes (2006); o sétimo e oitavo, por questões desenvolvidas por Teixeira et al. (2009); e os demais, por questões desenvolvidas na pesquisa gerencial Fucape das 200 maiores empresas do Estado do Espírito Santo - Edição 2010, com as devidas adequações para o ramo pesquisado. A Figura 3 apresenta a divisão dos blocos do questionário.

\begin{tabular}{cl}
\hline Blocos & \multicolumn{1}{c}{ Informações } \\
\hline 1 & Sobre o respondente e a cooperativa. \\
\hline 2 & Sobre a utilização dos serviços de consultoria externa. \\
\hline 3 & Sobre o número de empregados da cooperativa. \\
\hline 4 & Sobre o modelo de gestão. \\
\hline 5 & $\begin{array}{l}\text { Sobre a existência de um departamento específico de contabilidade gerencial e as principais tarefas do } \\
\text { departamento. }\end{array}$ \\
\hline 6 & Sobre as práticas de contabilidade gerencial adotadas. \\
\hline 7 & Sobre benefícios da implantação das ferramentas. \\
\hline 8 & Sobre fatores que motivam ou restringem a implantação das ferramentas. \\
\hline 9 & Sobre informações financeiras dos 10 últimos exercícios referentes às sobras líquidas antes da destinação aos \\
\hline 10 & Sobre o porte, utilizando-se informações de faturamento e ativo total dos últimos 10 exercícios. \\
\hline 11 & Informações específicas sobre a utilização do orçamento. \\
\hline 12 & Sobre a existência de incentivos para gestores. \\
\hline 13 & Relativas ao posicionamento estratégico, padrão contábil e governança. \\
\hline
\end{tabular}

Figura 3. Divisão de Blocos do Questionário

Fonte: Dados da pesquisa 
Com relação aos blocos 9 e 10, foi solicitado aos respondentes que informassem as sobras/perdas, patrimônio líquido, faturamento e ativo total dos últimos 10 exercícios. Poucos respondentes se dispuseram a fornecer os dados de período tão longo. Assim, foi-lhes solicitado que informassem os dados apenas dos exercícios de 2009 e 2010. Em relação à geração de caixa, mesmo com a solicitação apenas dos dois últimos exercícios, poucos se dispuseram a fornecer as informações, motivo pelo qual foi informado pelo pesquisador ao respondente que não era necessário fornecê-las, caso delas não dispusesse ou assim não quisesse. A intenção era incorporá-las ao rol das demais variáveis utilizadas como medida de desempenho, como complemento ao trabalho de Soutes (2006), o que não pôde ser feito.

\subsection{Métodos de Análise}

Similar ao estudo de Soutes (2006), foram aplicados testes estatísticos não paramétricos (Hill \& Hill, 2005, p. 195), submetendo os dados ao teste de significância de médias de duas amostras independentes, denominado "teste de Wilcoxon-Mann-Whitney ou, simplesmente, teste de Mann-Whitney" (Marôco, 2010, p. 321).

Com a obtenção dos dados de utilização de cada um dos artefatos, a amostra foi dividida entre cooperativas que utilizavam e que não utilizavam cada um dos artefatos, bem como o grupo daquelas que utilizavam os artefatos de contabilidade gerencial tradicionais e o grupo daquelas que utilizavam também os artefatos de contabilidade gerencial modernos.

Cada artefato foi testado com relação ao desempenho e ao porte das cooperativas que afirmaram utilizá-lo e não utilizá-lo. Para a análise de desempenho, utilizaram-se como referência as sobras ou perdas, a rentabilidade do patrimônio líquido e a rentabilidade do ativo. Para a análise de porte, como em Soutes (2006), utilizou-se como referência o ativo total e o faturamento.

A divisão dos grupos entre tradicionais e modernos seguiu metodologia similar à adotada por Soutes (2006). São modernos, do rol de artefatos selecionados para o estudo: teoria das restrições, custeio baseado em atividades, benchmarking, just-in-time, kaizen, custeio-meta, simulação, balanced scorecard, economic vallue added e Gecon, por constarem do $3^{\circ}$ e $4^{\circ}$ estágios da contabilidade gerencial propostos pelo Institute of Management Accountants, arrolados da Figura 2.

No bloco 6 do questionário, o respondente foi perguntado sobre os artefatos de contabilidade gerencial utilizados na cooperativa. Constaram do bloco 24 perguntas sobre a utilização dos 18 artefatos de contabilidade gerencial analisados neste estudo. Das 24 questões, 13 referiam-se aos artefatos modernos. Como em Soutes (2006), em algumas questões, a pergunta sobre a utilização do artefato foi feita de forma direta. Por exemplo: Para efeito gerencial, o custo dos produtos é calculado com base no método de custeio variável? Em outras, de forma indireta, sobre um procedimento ou conceito que implicava a afirmação ou informação da utilização de um artefato específico. Por exemplo: a cooperativa utiliza o conceito de margem de contribuição (receitas menos custos e despesas variáveis dos produtos)?

Foi solicitado ao respondente que assinalasse, em uma escala Likert, o seu grau de concordância com cada uma das questões, de acordo com as seguintes opções: discordo totalmente (DT), discordo (D), não concordo nem discordo (NC/ND), concordo (C), concordo totalmente (CT). Classificaram-se no grupo de cooperativas que utilizam artefatos de contabilidade gerencial modernos as que marcaram a opção "concordo totalmente ou "concordo parcialmente" em pelo menos 7 das 13 questões, seguindo e mesmo critério utilizado em Soutes (2006). Esse critério definiu a classificação da cooperativa como moderna, independentemente do número de questões que respondeu concordar, total ou parcialmente, referente aos artefatos classificados como tradicionais.

Para a análise de relação com o desempenho, utilizando-se das médias dos anos de 2009 e 2010, das sobras ou perdas de cada cooperativa, bem como a rentabilidade do ativo e a rentabilidade do patrimônio líquido, foi aplicado o teste de Mann-Whitney, que procurou identificar a diferença estatística, com nível de significância, bicaudal, de 5\%, ou seja, 2,5\% para cima ou para baixo, entre as médias das variá- 
veis que representavam o desempenho de cada um dos dois grupos que utilizavam, ou não, cada um dos artefatos analisados. Posteriormente, aplicou-se o mesmo teste ao grupo daquelas cooperativas que utilizavam os artefatos tradicionais, comparando-o ao grupo daquelas que utilizavam, além dos tradicionais, os artefatos modernos.

Para a análise de relação com o porte, utilizando-se das médias de faturamento e ativo total dos anos de 2009 e 2010, também foi aplicado o teste de Mann-Whitney para avaliar, com nível de significância de $5 \%$, possível relação com a utilização dos artefatos tradicionais e modernos.

\section{Análise dos Dados}

A análise dos dados é apresentada com uma amostra de 69 questionários recebidos. Apesar de as cooperativas serem do ramo agropecuário, a questão 1.6 do questionário solicitou que fosse informado qual era o principal insumo adquirido dos associados. Com base nas respostas, foi possível identificar que, das 69 respondentes, 36 (52,17\%) têm como principal produto o leite, 11 (15,94\%), o café, 4 (5,79\%), a soja, e $4(5,79 \%)$, o milho.

Quanto ao número de funcionários, 29 cooperativas (42,03\%) têm quadro abaixo de 50 funcionários, 10 cooperativas (14,49\%), entre 50 e 100 funcionários, e 30 cooperativas (43,48\%), acima de 100 funcionários.

\subsection{Perfil dos Respondentes}

O bloco 1 do questionário solicitava informações sobre o respondente e a cooperativa. Os dados evidenciaram, quanto à formação, que $36(52,17 \%)$ dos respondentes são graduados em Ciências Contábeis, 14 (20,29\%) em Administração e os demais em outras áreas do conhecimento. No total, há dois mestres, cinco especialistas, 49 graduados e 13 respondentes com superior incompleto. Interessante observar que, dos 69 respondentes, 65 afirmaram participar de cursos de reciclagem, evidenciando preocupação constante com a atualização do conhecimento.

Quanto ao tempo ocupando o cargo, os dados mostram que 32 (46,38\%) estão no cargo há menos de cinco anos, 13 (18,84\%), entre 5 e 10 anos, e apenas 14 (20,29\%) há mais de 15 anos, indicando uma possível renovação desses profissionais na cooperativa.

A questão 1.2 do questionário solicitou a informação sobre o ano de graduação do responsável pela contabilidade gerencial. Semelhantes aos resultados encontrados por Soutes (2006) e Teixeira et al. (2009), os dados indicam que em 34 (66,67\%) das 51 respostas, o tempo ocupando o cargo como responsável pela contabilidade gerencial, considerando o ano de graduação, é menor que 10 anos. Considerando que o tempo médio de existência das cooperativas é de 38,29 anos, pode-se afirmar que os dados indicam uma renovação desses profissionais nas cooperativas agropecuárias.

\subsection{Sobre a Utilização de Consultoria Externa}

No bloco 2 do questionário, as perguntas circunscreveram a utilização de consultoria externa. Na primeira questão, o respondente deveria informar se a cooperativa utilizava consultoria externa. Caso a resposta fosse sim, deveria assinalar em quais áreas, constantes do rol preestabelecido, com a possibilidade de indicar consultorias em outras áreas não constantes da questão.

De acordo com os dados, $56(81,16 \%)$ das 69 respondentes, afirmaram utilizar-se de consultoria externa, condizente com os estudos de Soutes (2006), nos quais $82(91,11 \%)$ das 90 respondentes fizeram a mesma afirmação. 
O resultado quanto aos tipos também é condizente com Soutes (2006): entre os seis tipos de consultoria mais utilizados pelas cooperativas, encontram-se planejamento estratégico (30\%), gestão de qualidade total (28,60\%), custos $(28,6 \%)$ e orçamento $(17,9 \%)$. Ressalta-se da análise dos dados a constatação de que o planejamento tributário se encontra em primeiro lugar, com utilização por $44,6 \%$ das cooperativas que possuem consultoria, ressaltando ainda que mais $8,9 \%$ afirmaram utilizar consultoria fiscal e tributária, evidenciando grande preocupação com essa área. Outras áreas citadas foram: implantação de gestão de logística, implantação de gestão baseada em valor, consultoria jurídica, segurança do trabalho, projetos de construções industriais e consultoria ambiental.

\subsection{Formalização do Modelo de Gestão e o Departamento de Contabilidade Gerencial}

O objetivo das questões do bloco 4 do questionário era verificar o nível de formalização do modelo de gestão. Os respondentes deveriam informar em uma escala Likert seu grau de concordância, assinalando as seguintes opções: discordo totalmente (DT), discordo (D), não concordo nem discordo (NC/ND), concordo (C), concordo totalmente (CT).

Os resultados se mostraram coincidentes com os apresentados por Soutes (2006). A média de 73,84 dos respondentes que disseram concordar totalmente e parcialmente indica um alto grau de formalização do modelo de gestão nas cooperativas agropecuárias.

O quinto bloco foi composto por cinco questões sobre a existência de um departamento ou setor específico que tratasse das informações de contabilidade gerencial e suas principais tarefas. Os resultados assemelham-se aos encontrados por Soutes (2006), indicando que, para 61 (88,5\%) das empresas respondentes que afirmaram concordar totalmente e parcialmente, há um departamento específico responsável pelas informações contábil-gerenciais. Esses resultados não causam surpresa em função de exigências legais para que as cooperativas usufruam deste "status" societário e dos benefícios fiscais, sobretudo relativos ao IRPJ, CSLL, PIS e Cofins.

Também para 88,5\% das cooperativas, uma das principais funções da contabilidade gerencial é assessorar a diretoria e todos os gestores em assuntos relativos a impactos econômico-financeiros.

Ressalte-se que os altos índices, tanto em relação à formalização do modelo de gestão quanto à existência de um departamento específico de contabilidade gerencial, podem estar enviesados, pois a maioria das respostas foi dada pelo contador ou pelo gerente da área administrativa da cooperativa. Não se verificou a mesma estrutura de respondentes em outras pesquisas, mas ressalta-se que a estrutura de gestão, principalmente contábil, está relacionada à exigências legais relativas à estrutura societária e benefícios tributários.

\subsection{Benefícios da Implantação das Ferramentas}

Os resultados sobre a percepção dos respondentes relacionados aos benefícios da implantação dos artefatos de contabilidade gerencial são apresentados na Tabela 1. 
Tabela 1

Benefícios da Implantação das Ferramentas (Escala 1 A 7)

\begin{tabular}{ll}
\hline \multicolumn{1}{c}{ Benefícios percebidos pelo respondente } & Média \\
\hline Apoio à tomada de decisões & 2,58 \\
\hline Melhoria no controle do gerenciamento de custos & 2,88 \\
\hline Outros & 2,94 \\
\hline Melhoria nas medidas de desempenho & 3,09 \\
\hline Suporte para preparação dos relatórios financeiros & 3,39 \\
\hline Melhoria no controle orçamentário & 3,72 \\
\hline Melhoria no processo de engenharia de valor & 3,87 \\
\hline
\end{tabular}

Fonte: Dados da Pesquisa

A questão constante do bloco 7 do questionário solicitou ao respondente que assinalasse, em ordem de prioridade de 1 a 7 (sendo 1 para o mais importante e 7 para o menos importante), os benefícios percebidos com a implantação dos artefatos de contabilidade gerencial.

Pela ordem, o item mais importante na implantação das ferramentas é o apoio à tomada de decisões, com a menor média, 2,58 , seguido da melhoria no controle do gerenciamento de custos, com média de 2,88. Os resultados, com relação aos itens de maior importância, mostram-se idênticos aos encontrados em Teixeira et al. (2009) e Soutes e De Zen (2005). Os itens menos importantes foram a melhoria no processo de engenharia de valor, com média de 3,87, e melhoria no controle orçamentário, com média de 3,72 . Importante ressaltar que houve divergência no critério dos respondentes, com 39 (56,5\%), enumerando em ordem crescente de 1 a 7 e 30 (43,5\%), sem obediência a essa ordem, repetindo, por vezes, a mesma ordem de prioridade para mais de um item. Entretanto, esse fato parece não ter comprometido o resultado.

\subsection{Fatores Restritivos e Motivadores da Implantação das Ferramentas}

As questões do bloco 8 do questionário solicitaram aos respondentes que assinalassem, em ordem de prioridade, de 1 a 7 (sendo 1 para o mais importante e sete para o menos importante), quais fatores entendiam como restritivos ou motivadores da implantação de ferramentas de contabilidade gerencial. Os resultados constam das Tabelas 2 e 3.

Tabela 2

\section{Fatores Motivadores da Adoção das Ferramentas}

\begin{tabular}{ll}
\hline \multicolumn{1}{c}{ Fatores que podem motivar a adoção } & Média \\
\hline Falta de participação/comprometimento dos envolvidos & 2,72 \\
\hline Outros & 2,72 \\
\hline Falta de conhecimento e experiência da equipe & 3,01 \\
\hline Falta de recursos & 3,09 \\
\hline Falta de tecnologia adequada & 3,10 \\
\hline Relação custos versus benefício & 3,61 \\
\hline Falta de necessidade de utilização dessas ferramentas & 3,67 \\
\hline
\end{tabular}

Fonte: Dados da Pesquisa

De acordo com os respondentes, pela ordem, o item que mais motiva a adoção das ferramentas, com a menor média, 2,72, é a falta de participação/comprometimento dos envolvidos. Os resultados são similares aos encontrados por Teixeira et al. (2009). Os fatores que menos motivam na ótica dos respondentes são a falta de necessidade de utilização das ferramentas, com média de 3,67, e a relação custo versus benefício, com média de 3,61. 
Tabela 3

\section{Fatores Restritivos à Adoção das Ferramentas}

\begin{tabular}{lc}
\hline \multicolumn{1}{c}{ Fatores que podem restringir a adoção } & Média \\
\hline Comprometimento/parcialmente dos envolvidos no processo & 3,09 \\
\hline Conhecimento e experiência da equipe interna disponível & 3,19 \\
\hline Disponibilidade de tais ferramentas dentro do ERP padrão & 3,22 \\
\hline Tecnologia adequada disponível & 3,32 \\
\hline Recursos disponíveis & 3,55 \\
\hline Relação custos versus benefício & 3,86 \\
\hline Adoção de tais ferramentas pelos concorrentes & 4,57 \\
\hline
\end{tabular}

Fonte: Dados da Pesquisa

De acordo com os respondentes (Tabela 3), pela ordem, o item que mais restringe a adoção das ferramentas é o comprometimento/parcialmente dos envolvidos no processo, com média de 3,09, seguido do conhecimento e experiência da equipe interna disponível. Os resultados são similares aos encontrados por Teixeira et al. (2009) e Soutes e De Zen (2005). Importante ressaltar que, da mesma forma identificada em Teixeira et al. (2009), o comprometimento dos envolvidos no processo é visto como o fator que mais pode motivar e, ao mesmo tempo, restringir a adoção das ferramentas de contabilidade gerencial. Os fatores que menos restringem na ótica dos respondentes são a adoção de tais ferramentas pelos concorrentes, média 4,57, e a relação custos versus benefícios, com média de 3,86.

\subsection{Sistemas de Incentivo}

No bloco 12 foi perguntado se a cooperativa possuía algum sistema de incentivo aos gestores e demais empregados, colocando como alternativas o bônus anual, o programa de participação em resultados e planos de incentivo de longo prazo, podendo o respondente citar outros existentes. Com relação ao Bônus anual e ao Programa de Participação em Resultados - PPR, 8 (11,59\%) cooperativas responderam "sim" e $61(88,41 \%)$ responderam "não" praticar esses incentivos. Com relação a planos de incentivos de longo prazo, a resposta foi "não" para as $69(100 \%)$ cooperativas.

\subsection{Utilização dos Artefatos de Contabilidade Gerencial}

No bloco 6 do questionário, o respondente foi perguntado sobre os artefatos de contabilidade gerencial utilizados na cooperativa.

A Tabela 4 apresenta os dados de 68 cooperativas: uma das respondentes recusou-se a informar os dados relativos a sobras, patrimônio líquido, faturamento e ativo total, fundamentais para a análise de relação entre a utilização dos artefatos com rentabilidade e porte.

Os resultados, seguindo a metodologia adotada para este estudo, apontam como artefatos mais utilizados nas cooperativas agropecuárias: a simulação (77,9\%), o custeio por absorção e o orçamento $(64,7 \%)$, e o custeio variável $(63,2 \%)$. Como artefatos menos utilizados, coincidentemente todos modernos, destacam-se o balanced scorecard e a filosofia kaizen (14,7\%), o EVA (20,6\%), o ABC (28\%) e o just-in-time e o custeio meta (29,4\%). Em Teixeira et al. (2009), os artefatos mais utilizados são: o sistema de informações gerenciais, o orçamento, o custeio por absorção e a análise por centro de responsabilidade. Os menos utilizados são os mesmos encontrados nas cooperativas agropecuárias evidenciadas acima. Em Soutes (2006), os mais utilizados são simulações, benchmarking, custeio variável, descentralização e custeio por absorção. Os menos utilizados: $\mathrm{ABC}$, just-in-time, kaizen, preço de transferência e custeio meta. 
Em Reginato (2010), os artefatos mais utilizados são o orçamento, EBITDA, ROI, simulação e custeio variável. Os menos utilizados são a teoria das restrições, Kaizen, EVA, just-in-time e o balanced scorecard. É possível notar, comparando com os estudos anteriores, coincidências nas ferramentas mais utilizadas e, ainda, coincidências mais acentuadas nas ferramentas menos utilizadas.

Tabela 4

Práticas de Contabilidade Gerencial

\begin{tabular}{|c|c|c|c|c|c|c|}
\hline Práticas de Contabilidade Gerencial & DT & D & NC/ND & C & CT & TOTAL \\
\hline Orçamento & 14,7 & 8,8 & 11,8 & 30,9 & 33,8 & $100 \%$ \\
\hline Simulação (1) & 4,4 & 2,9 & 14,7 & 35,3 & 42,6 & $100 \%$ \\
\hline Simulação (2) & 19,1 & 5,9 & 16,2 & 32,4 & 26,5 & $100 \%$ \\
\hline Custeio Variável (1) & 20,6 & 7,4 & 11,8 & 22,1 & 38,2 & $100 \%$ \\
\hline Descentralização & 29,4 & 11,8 & 23,5 & 23,5 & 11,8 & $100 \%$ \\
\hline Custeio variável (2) & 8,8 & 13,2 & 14,7 & 25,0 & 38,2 & $100 \%$ \\
\hline Teoria das restrições (1) & 29,4 & 11,8 & 19,1 & 20,6 & 19,1 & $100 \%$ \\
\hline Custeio padrão (1) & 10,3 & 5,9 & 23,5 & 38,2 & 22,1 & $100 \%$ \\
\hline Custeio padrão (2) & 22,1 & 8,8 & 22,1 & 25,0 & 22,1 & $100 \%$ \\
\hline Custeio baseado em atividade (ABC) & 38,2 & 5,9 & 27,9 & 22,1 & 5,9 & $100 \%$ \\
\hline Benchmarking (1) & 16,2 & 7,4 & 19,1 & 29,4 & 27,9 & $100 \%$ \\
\hline Benchmarking (2) & 23,5 & 5,9 & 20,6 & 29,4 & 20,6 & $100 \%$ \\
\hline Balanced Scorecard & 54,4 & 4,4 & 26,5 & 11,8 & 2,9 & $100 \%$ \\
\hline Economic Value Added (EVA) & 45,6 & 5,9 & 27,9 & 14,7 & 5,9 & $100 \%$ \\
\hline Teoria das restrições (2) & 16,2 & 2,9 & 22,1 & 32,4 & 26,5 & $100 \%$ \\
\hline Valor presente & 16,2 & 2,9 & 19,1 & 27,9 & 33,8 & $100 \%$ \\
\hline Moeda constante & 17,6 & 1,5 & 19,1 & 27,9 & 33,8 & $100 \%$ \\
\hline Preço de transferência (1) & 17,6 & 2,9 & 19,1 & 20,6 & 39,7 & $100 \%$ \\
\hline Preço de transferência (2) & 36,8 & 7,4 & 16,2 & 25,0 & 14,7 & $100 \%$ \\
\hline Gecon & 22,1 & 2,9 & 11,8 & 20,6 & 42,6 & $100 \%$ \\
\hline Just-in-time & 39,7 & 4,4 & 26,5 & 19,1 & 10,3 & $100 \%$ \\
\hline Kaizen & 47,1 & 5,9 & 32,4 & 11,8 & 2,9 & $100 \%$ \\
\hline Custeio-meta & 35,3 & 4,4 & 30,9 & 16,2 & 13,2 & $100 \%$ \\
\hline Custeio por Absorção & 4,4 & 0,0 & 30,9 & 29,4 & 35,3 & $100 \%$ \\
\hline Bloco 6 - (Média Geral) & 24,6 & 5,9 & 21,1 & 24,6 & 23,8 & $100 \%$ \\
\hline
\end{tabular}

Fonte: Dados da Pesquisa

A análise de relação entre utilização dos artefatos e o desempenho foi feita com base nos dados fornecidos dos anos de 2009 e 2010 em relação à média das sobras antes da destinação para os fundos obrigatórios ou perdas, da rentabilidade do patrimônio líquido e da rentabilidade do ativo. A análise relacionada à utilização dos artefatos e porte também foi feita com base na média dos dados fornecidos dos anos de 2009 e 2010, relativos ao faturamento e ativo total. A justificativa para utilização dos dados de 2009 e 2010 deu-se pelo não fornecimento dos dados anteriores a este período pela maioria das cooperativas. Destaca-se que seguindo Soutes (2006), a questão "A cooperativa calcula o custo financeiro dos estoques" é que está associada ao sistema Gecon (sistema de Gestão Econômica). 
Baseada em cada questão do bloco 6 do questionário, a análise foi feita em relação a cada um dos artefatos de contabilidade gerencial respectivos, dividindo-se as cooperativas em 2 grupos, formados pelas que disseram concordar total e parcialmente e pelas que disseram discordar total, parcialmente e não concordar nem discordar. Por fim, as análises de relação com desempenho e porte foram feitas com a divisão das cooperativas em dois grupos: tradicionais e modernas.

\subsubsection{Resultados por Estágio}

Cada linha das Tabelas 5 a 8, por estágios de evolução da contabilidade gerencial, apresenta o resultado do nível de significância (Asymp. Sig), obtido em função dos resultados dos testes de Mann-Whitney para cada grupo em que a amostra foi dividida.

Tabela 5

Artefatos Tradicionais ( $1^{\circ}$ Estágio)

\begin{tabular}{lccccc}
\hline \multicolumn{1}{c}{ Artefatos } & Sobras & Rentabilidade PL & Rentabilidade Ativo & Faturamento & Ativo Total \\
\hline Custeio variável (1) & 0,251 & 0,817 & 0,740 & 0,463 & 0,519 \\
\hline Custeio variável (2) & 0,250 & 0,087 & 0,176 & 0,442 & 0,755 \\
\hline Custeio-padrão (1) & 0,778 & 0,441 & 0,535 & 0,836 & 0,511 \\
\hline Custeio-padrão (2) & 0,302 & 0,606 & 0,539 & 0,291 & 0,572 \\
\hline Custeio por absorção & 0,555 & 0,342 & 0,426 & 0,293 & 0,228 \\
\hline
\end{tabular}

Fonte: Dados da Pesquisa

Tabela 6

Artefatos Tradicionais ( ${ }^{\circ}$ Estágio)

\begin{tabular}{lccccc}
\hline \multicolumn{1}{c}{ Artefatos } & Sobras & Rentabilidade PL & Rentabilidade Ativo & Faturamento & Ativo Total \\
\hline Orçamento & 0,040 & 0,010 & 0,015 & 0,170 & 0,218 \\
\hline Descentralização & 0,355 & 0,336 & 0,182 & 0,349 & 0,441 \\
\hline Valor Presente & 0,870 & 0,350 & 0,325 & 0,781 & 0,412 \\
\hline Moeda Constante & 0,496 & 0,158 & 0,231 & 0,910 & 0,724 \\
\hline Preço de Transferência (1) & 0,905 & 0,560 & 0,955 & 0,325 & 0,721 \\
\hline Preço de Transferência (2) & 0,768 & 0,141 & 0,159 & 0,527 & 0,995 \\
\hline
\end{tabular}

Fonte: Dados da Pesquisa

Tabela 7

Artefatos Modernos ( $3^{\circ}$ Estágio)

\begin{tabular}{|c|c|c|c|c|c|}
\hline Artefatos & Sobras & Rentabilidade PL & Rentabilidade Ativo & Faturamento & Ativo Total \\
\hline Teoria das Restrições (1) & 0,665 & 0,730 & 0,535 & 0,797 & 0,535 \\
\hline Teoria das Restrições (2) & 0,065 & 0,645 & 0,213 & 0,100 & 0,132 \\
\hline $\mathrm{ABC}$ & 0,465 & 0,727 & 0,571 & 0,206 & 0,424 \\
\hline Benchmarking (1) & 0,660 & 0,468 & 0,438 & 0,123 & 0,132 \\
\hline Benchmarking (2) & 0,768 & 0,632 & 0,650 & 0,206 & 0,173 \\
\hline Just-in-Time & 0,904 & 0,829 & 0,419 & 0,914 & 0,946 \\
\hline Kaizen & 0,568 & 0,904 & 0,436 & 0,299 & 0,755 \\
\hline Custeio-Meta & 0,270 & 0,716 & 0,788 & 0,518 & 0,353 \\
\hline
\end{tabular}

Fonte: Dados da Pesquisa 
Tabela 8

Artefatos Modernos (4 estágio)

\begin{tabular}{|c|c|c|c|c|c|}
\hline Artefatos & Sobras & Rentabilidade PL & Rentabilidade Ativo & Faturamento & Ativo Total \\
\hline Simulação (1) & 0,217 & 0,002 & 0,021 & 0,935 & 0,830 \\
\hline Simulação (2) & 0,575 & 0,301 & 0,418 & 0,672 & 0,755 \\
\hline Balanced Scorecard & 0,917 & 0,972 & 0,678 & 0,166 & 0,283 \\
\hline Economic Vallue Added & 0,467 & 0,457 & 0,617 & 0,396 & 0,750 \\
\hline Gecon & 0,924 & 0,294 & 0,300 & 0,894 & 0,804 \\
\hline
\end{tabular}

Fonte: Dados da Pesquisa

Em sua grande maioria, não há evidências de diferenças estatísticas significativas com relação à rentabilidade e porte das empresas que informaram utilizar e não utilizar cada um dos artefatos. Os resultados, também em sua grande maioria, são coincidentes com os obtidos por Soutes (2006).

Diferenças estatísticas significativas foram encontradas apenas com relação ao desempenho, para os artefatos orçamento e a questão 1 de simulação de receitas, custos e margem. Essas diferenças foram identificadas nas variáveis "rentabilidade do ativo" e "rentabilidade do patrimônio líquido", no entanto, não foram evidenciadas para as sobras ou perdas.

\subsubsection{Artefatos Modernos e Tradicionais}

Do rol de questões constantes do bloco 6 do questionário, 13 questões estavam relacionadas a artefatos classificados como modernos, por constarem do $3^{\circ} \mathrm{e} 4^{\circ}$ estágios da contabilidade gerencial propostos pelo Institute of Management Accountants. As cooperativas que assinalaram sete ou mais desses artefatos foram classificadas como modernas, enquanto as restantes classificaram-se como tradicionais. Após a análise, foi identificado que apenas 19 das 68 respondentes foram classificadas como modernas, conforme consta da Tabela 9.

Tabela 9

Classificação entre Tradicionais e Modernas

\begin{tabular}{lcc} 
& Frequência & Percentual \\
\hline Artefatos tradicionais & 49 & 72,06 \\
\hline Artefatos modernos & 19 & 27,94 \\
\hline Total & 68 & 100,0 \\
\hline
\end{tabular}

Fonte: Dados da Pesquisa

A Tabela 10 evidencia os valores obtidos para os testes de Mann-Whitney, Wilcoxon e da estatística Z, além do resultado do nível de significância (Asymp. Sig). Após a classificação, foram feitos os testes para a verificação de evidências de diferença estatisticamente significativa entre as cooperativas que se utilizam e não se utilizam das práticas modernas de contabilidade gerencial.

Tabela 10

Teste Estatístico (Artefatos Modernos e Tradicionais)

\begin{tabular}{lccccc} 
& Sobras & Rentabilidade PL & Rentabilidade Ativo & Faturamento & Ativo Total \\
\hline Mann-Whitney U & 417,000 & 444,000 & 452,000 & 455,000 & 459,000 \\
\hline Wilcoxon W & 607,000 & 1669,000 & 1677,000 & 1680,000 & 649,000 \\
\hline Z & $-0,663$ & $-0,294$ & $-0,185$ & $-0,144$ & $-0,089$ \\
\hline Asymp. Sig. (2-tailed) & 0,507 & 0,769 & 0,854 & 0,886 & 0,929 \\
\hline
\end{tabular}

Fonte: Dados da Pesquisa 
A análise de relação com o desempenho baseada nas sobras, na rentabilidade do ativo e na rentabilidade do patrimônio líquido evidencia não haver diferença estatisticamente significativa para o grupo das empresas que utilizam e não utilizam os artefatos modernos. O resultado é divergente do encontrado em Soutes (2006), mas convergente com Teixeira et al. (2009). Na análise relacionada ao porte, não há evidências de diferença estatisticamente significativa para o ativo total e faturamento. Nesse ponto, converge-se com os resultados de Soutes (2006). A análise relacionada ao porte não foi feita em Teixeira et al. (2009).

\section{Considerações Finais}

O objetivo deste trabalho foi verificar a utilização de artefatos tradicionais e modernos de contabilidade gerencial e o seu relacionamento com porte e desempenho financeiro. A pesquisa foi desenvolvida com 68 cooperativas agropecuárias do Estado de Minas Gerais e teve como principais respondentes os seus contadores e administradores.

Com base nos estudos anteriores, três hipóteses foram testadas. A hipótese 1 afirmou que as cooperativas agropecuárias do Estado de Minas Gerais não utilizavam os artefatos modernos de contabilidade gerencial. Os resultados a confirmaram parcialmente, uma vez que evidenciaram a prevalência de utilização dos artefatos tradicionais de contabilidade gerencial pela maioria das cooperativas, 49 das 69 . São, portanto, convergentes com os estudos de Sulaiman et al. (2004), Chenhall e Langfield-Smith (1998), Teixeira et al. (2009) e Reginato (2010), mas divergentes com relação aos estudos de Soutes (2006).

Para as cooperativas agropecuárias de Minas Gerais, confirmou-se, também parcialmente, o gap entre teoria e prática sobre o qual fala Langfield-Smith (2008), o que diverge das afirmações de Soutes e Guerreiro (2007), segundo as quais as ponderações sobre a existência desse gap poderiam estar defasadas.

A hipótese 2 fez associação entre a utilização dos artefatos modernos com porte diferenciado. As variáveis utilizadas para porte foram o faturamento e o ativo total médios dos anos de 2009 e 2010. Os resultados encontrados rejeitaram a hipótese, não havendo evidências de diferença estatística entre as cooperativas classificadas como tradicionais e aquelas classificadas como modernas. O resultado é convergente com Soutes (2006). Entretanto, as 19 cooperativas classificadas como modernas apresentam, respectivamente, faturamentos e ativos médios 2,04 e 3,41 vezes maiores que aquelas classificadas como tradicionais. Nessa ótica, os dados alinham-se à ponderação de Langfield-Smith (1998) para o qual há uma possível relação entre tamanho e recursos para utilização de novos artefatos contábeis. Alinham-se, também, às evidências de Gonzaga et al. (2010) a relação entre o tamanho e maior quantidade de utilização de alguns artefatos.

A hipótese 3 associou a utilização dos artefatos modernos com o desempenho financeiro diferenciado. As variáveis utilizadas para desempenho foram as médias das sobras/perdas antes da destinação para os fundos obrigatórios, a rentabilidade do PL e a rentabilidade do ativo os anos de 2009 e 2010 . Essa hipótese também foi rejeitada. Os resultados encontrados não evidenciaram relação entre a utilização de artefatos modernos com desempenho financeiro diferenciado, ou seja, o grupo classificado como tradicional apresentou as mesmas médias de desempenho do grupo classificado como moderno. O resultado é convergente com Teixeira et al. (2009), mas divergente de Soutes (2006).

$\mathrm{Na}$ análise de cada artefato, composta pelo grupo das cooperativas que afirmaram utilizá-los em relação ao grupo das cooperativas que afirmaram não utilizá-los, evidenciou-se diferença estatisticamente significativa apenas em relação ao orçamento e à simulação de receitas, custos e margem. A evidência deu-se com relação ao desempenho, nas variáveis rentabilidade do patrimônio líquido e rentabilidade do ativo, não sendo constatada para as sobras/perdas. Especificamente em relação ao orçamento, Espejo (2008) encontrou associação entre certos atributos e desempenho financeiro.

A principal contribuição desta pesquisa para a literatura foi a ampliação do espaço amostral, utilizando-se de dados de cooperativas de um único estado, Minas Gerais, de um segmento específico, o cooperativismo agropecuário, diferenciando-se dos estudos anteriores, cujo critério de seleção da amostra foi o porte (Soutes, 2006; Espejo, 2008; Teixeira et al., 2009; Reginato, 2010; Matos, 2010 \& Gonzaga et al., 2010). 
Adicionalmente, foi possível comparar os resultados obtidos com aqueles já evidenciados em estudos anteriores, realizados no Brasil e no exterior. É importante ressaltar que, mesmo utilizando-se de amostra composta por sociedades de um segmento específico e apenas de um estado, os resultados são semelhantes aos encontrados nas pesquisas já realizadas. Há coincidência em relação aos artefatos de contabilidade gerencial mais utilizados (simulação, custeio por absorção, orçamento e custeio variável) e os menos utilizados (balanced scorecard, Kaizen, EVA, ABC, just-in-time e custeio meta) com aqueles encontrados em Soutes (2006), Teixeira et al. (2009) e Reginato (2010).

Os dados referentes à renovação dos profissionais responsáveis pela área de contabilidade gerencial, existência de um departamento específico de contabilidade gerencial, formalização do modelo de gestão, utilização de consultoria externa, benefícios da implantação dos artefatos e fatores restritivos e motivadores da sua adoção são similares aos encontrados em Soutes (2006) e Teixeira et al. (2009)

Com relação aos sistemas de incentivos aos gestores e demais empregados, as cooperativas praticamente não os utilizam. Apenas 11,59\% possuem bônus anual e programa de participação em resultados. Nenhuma cooperativa utiliza-se de planos de incentivo em longo prazo.

Cabe destacar as limitações dessa análise. A pesquisa foi feita por meio de questionário enviado por e-mail e, embora a maioria dos respondentes tenha formação em Contabilidade ou Administração, o que poderia conferir maior confiabilidade às respostas, pode ter havido o não entendimento parcial ou total de algumas questões que, em entrevista, poderiam ser mais bem debatidas e, havendo dúvidas, poderiam ser dirimidas. Em entrevista, a percepção sobre a utilização, ou não, de alguma ferramenta também poderia ter sido mais bem evidenciada. O estudo não pode ter seus resultados extrapolados para os demais ramos do cooperativismo e nem para outros estados.

Sugere-se, para outras pesquisas, ampliar as ferramentas de análise estatística e ainda estender a pesquisa aos demais ramos do cooperativismo em Minas Gerais e às cooperativas de outros estados da Federação. A mesma pesquisa também pode ser feita em âmbito nacional para o ramo agropecuário, buscando mais e melhores evidências da utilização dos artefatos de contabilidade gerencial e respectivos benefícios para as cooperativas brasileiras.

\section{Referências}

Atkinson, A.T., Banker, R.D., \& Kaplan, R.S. (2000). Contabilidade Gerencial. (1a ed.). São Paulo: Atlas.

Borinelli, M. L. (2006). Estrutura conceitual básica de controladoria: sistematização à luz da teoria e da práxis. Tese de Doutorado, Faculdade de Economia, Administração e Contabilidade da USP, São Paulo, SP, Brasil.

Lei 5.764, de 16 de dezembro de 1971 (1971). Define a Política Nacional de Cooperativismo, institui o regime jurídico das sociedades cooperativas, e dá outras providências. Diário Oficial da União. Brasília, DF: Ministério da Fazenda.

Carvalho, F.L. de, \& Bialoskorski, S. Neto. (2007). Um Ensaio sobre a Análise de Desempenho em Cooperativas Agropecuárias. Anais do Congresso USP de Controladoria e Contabilidade, São Paulo, SP, Brasil, 7.

Chenhall, R.H., \& Langfield-Smith, K. (1998). Adoption and benefits of management accounting practices: an Australian study. Management Accounting Research, 9(1), 1-19.

Creswell, J.W. (2007). Projeto de pesquisa: métodos qualitativo, quantitativo e misto. (2a ed.). Porto Alegre: Artmed.

Davila, A., \& Foster, G. (2007). Management control systems in early-stage startup companies. Accounting Review, 82(4), 907-937.

Espejo, M.M. dos S.B. (2008). Perfil dos atributos do sistema orçamentário sob a perspectiva contingencial: uma abordagem multivariada. Tese de Doutorado Faculdade de Economia, Administração e Contabilidade da USP, São Paulo, SP, Brasil. Recuperado de http://www.teses.usp.br/teses/disponiveis/12/12136/tde-30062008-141909/ 
Gonzaga, R. P., Da Luz, A.T.M., Guimarães, T.N., \& Valerio Jr., V.B. (2010). Associação entre práticas de contabilidade gerencial e tamanho das empresas: um estudo empírico. Anais da Associação Nacional Dos Programas De Pós-Graduação Em Ciências Contábeis, Natal, RN, Brasil, 4.

Guerreiro, R. Cornachione Jr. E.B., \& Soutes, D.O. (2010). A Utilização de Artefatos Modernos de Contabilidade Gerencial por Empresas Brasileiras. Anais do Encontro Da Anpad, Rio de Janeiro, RJ, Brasil, 34 .

Hill, M.M., \& Hill, A. (2005). Investigação por questionário. (2a ed.) Lisboa.

Horngren, C.T., Foster, G., \& Datar, S.M. (2000). Contabilidade de Custos (9a ed.) Rio de Janeiro: LTC.

Internacional Federation of Accountants. (1998). Internacional Management Accounting Practice 1. Recuperado de http://www.mia.org.my/handbook/guide/imap/imap_1.htm

Langfield-Smith, K. (2008). Strategic management accounting: how far have we come in 25 years? Accounting, Auditing \& Accountability Journal, 21(2), 204-228.

Marôco, J. (2010). Análise estatística com o PASW statistics. (1a ed). Pêro Pinheiro: ReportNumber.

Martins, G. de A. (2000). Manual para elaboração de monografias e dissertações. (2a ed.) São Paulo: Atlas.

Matos, E.R.J. de. (2010). Perfil do sistema de controle gerencial sob a perspectiva da teoria da contingência. Tese de Doutorado, Faculdade de Economia, Administração e Contabilidade, USP, São Paulo, SP, Brasil. Recuperado de http://www.teses.usp.br/teses/disponiveis/12/12136/tde-10052010-143511/

Organização das Cooperativas do Estado de Minas Gerais. (2010). Anuário do Cooperativismo Mineiro - Maiores Cooperativas de Minas Gerais ano 2010. Recuperado de http://www.ocemg.org.br/pagina/146/anuario-do-cooperativismo-mineiro.aspx

Oliveira, A.B.S., Célice, E.S., Cecconello, A.R., \& Di G, W.A.B., Kounrouzan, M.C., Barbosa, C.B. (2003). Métodos e técnicas de pesquisa em contabilidade. (1a ed.) São Paulo: Saraiva.

Otley, D.T. (1980). The Contingency theory or management accounting: achievements and prognosis. Accounting Organizations and Society. 5(4), 413-428.

Reginato, L. (2010). Um estudo setorial sobre as relações entre variáveis ambientais externas, modelos de gestão, controles gerenciais e desempenhos das empresas. 2010. Tese de Doutorado, Faculdade de Economia, Administração e Contabilidade da USP, São Paulo, SP, Brasil. Recuperado de http://www. teses.usp.br/teses/disponiveis/12/12136/tde-15042010-132200/

Shank, J.K., \& Govindarajan, V. (1997). A Revolução dos custos: como reinventar e redefinir sua estratégia de custos para vencer em mercados crescentemente competitivos. (2a ed.) Rio de Janeiro: Campus.

Soutes, D.O., \& De Zen, M.J. de C.M. (2005). Estágios evolutivos da Contabilidade Gerencial em empresas brasileiras. Anais do Congresso USP De Contabilidade, São Paulo, SP, Brasil, 5.

Soutes, D.O. (2006). Uma investigação do uso de artefatos da contabilidade gerencial por empresas brasileiras. Dissertação de Mestrado, Faculdade de Economia, Administração e Contabilidade da USP, São Paulo, SP, Brasil.

Soutes, D.O. (2007) Custo Total de Propriedade (TCO): É importante? Para quem? Ciências Sociais Aplicadas em Revista, 7(13), 83-105. 2007. Paraná: Unioeste

Soutes, D.O., \& Guerreiro, R. (2007). Uma investigação do uso de artefatos da contabilidade gerencial por empresas brasileiras. Anais do Encontro da Anpad, Rio de janeiro, RJ, Brasil, 31.

Sulaiman, M. bt., Ahmad, N.N.N., \& Alwi, N. (2004). Management accounting practices in selected Asian countries: A review of the literature. Managerial Auditing Journal, 4(19), 493-508.

Teixeira, A., Gonzaga, R.P., Santos, A.V.S.M., \& Nossa, V. (2011). A Utilização de ferramentas de contabilidade gerencial nas empresas do estado do Espírito Santo. Brazilian Business Review, 8(3), 108-127. 